\title{
Supplementary materials for Evaluation of the absorption Ångström exponents for traffic and wood burning in the Aethalometer based source apportionment using radiocarbon measurements of ambient aerosol
}

P. Zotter ${ }^{1, \#}$, H. Herich ${ }^{2}$, M. Gysel ${ }^{1}$, I. El-Haddad ${ }^{1}$, Y.L. Zhang ${ }^{1,3,4,5, \dagger}$, G. Močnik ${ }^{6,7}$, C. Hüglin $^{2}$, U. Baltensperger ${ }^{1}$, S. Szidat ${ }^{3,4}$, A.S.H. Prévôt ${ }^{1}$

${ }^{1}$ Laboratory of Atmospheric Chemistry, Paul Scherrer Institute (PSI), 5232 Villigen PSI, Switzerland

${ }^{2}$ Laboratory for Air Pollution and Environmental Technology, Swiss Federal Laboratories for Materials Science and Technology (Empa), Überlandstrasse 129, 8600 Dübendorf, Switzerland

${ }^{3}$ Department of Chemistry and Biochemistry, University of Bern, Bern, Switzerland

${ }^{4}$ Oeschger Centre for Climate Change Research, University of Bern, Bern, Switzerland

${ }^{5}$ Laboratory of Radiochemistry and Environmental Chemistry, Paul Scherrer Institute (PSI), 5232 Villigen PSI, Switzerland

${ }^{6}$ Aerosol d.o.o., Research and Development Department., Ljubljana, Slovenia

${ }^{7}$ Condensed Matter Physics Department, Jožef Stefan Institute, Ljubljana, Slovenia

${ }^{\#}$ now at: Lucerne University of Applied Sciences and Arts, School of Engineering and Architecture, Bioenergy Research, Technikumstrasse 21, CH-6048 Horw, Switzerland

${ }^{\dagger}$ now at: Yale-NUIST Center on Atmospheric Environment, Nanjing University of Information Science and Technology, 210044, Nanjing, China

Correspondence to: A.S.H. Prévôt (andre.prevot@psi.ch) 


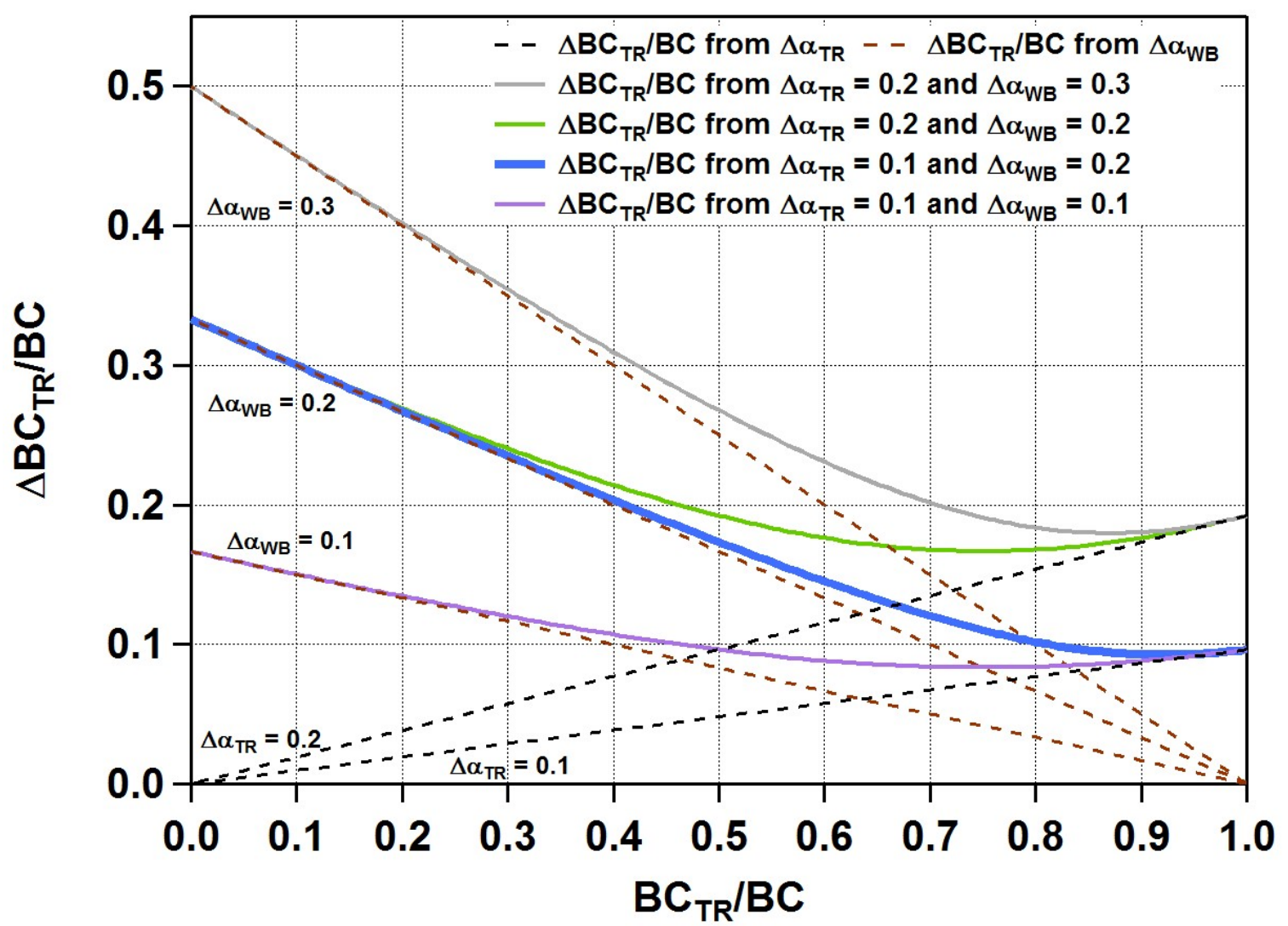

Figure $\mathrm{S} 1$ : Residuals of $\mathrm{BC}_{\mathrm{TR}} / \mathrm{BC}$ compared to $\mathrm{EC}_{\mathrm{F}} / \mathrm{EC}\left(\Delta \mathrm{BC}_{\mathrm{TR}} / \mathrm{BC}\right)$ as a function of $\mathrm{BC}_{\mathrm{TR}} / \mathrm{BC}$ calculated with $\alpha_{\mathrm{TR}}=0.90$ and $\alpha_{\mathrm{WB}}=1.68$ and using the wavelength pair $470 \mathrm{~nm}$ and $950 \mathrm{~nm}$. The brown and black dashes lines denote the residuals of $\mathrm{BC}_{\mathrm{TR}} / \mathrm{BC}$ with respect to an error of $\alpha_{\mathrm{WB}}$ and $\alpha_{\mathrm{TR}}\left(\Delta \alpha_{\mathrm{WB}}\right.$ and $\left.\Delta \alpha_{\mathrm{TR}}\right)$, respectively, and the solid coloured lines represent the errors in $\mathrm{BC}_{\mathrm{TR}} / \mathrm{BC}$ with respect to errors in both, $\alpha_{\mathrm{WB}}$ and $\alpha_{\mathrm{TR}}$. 


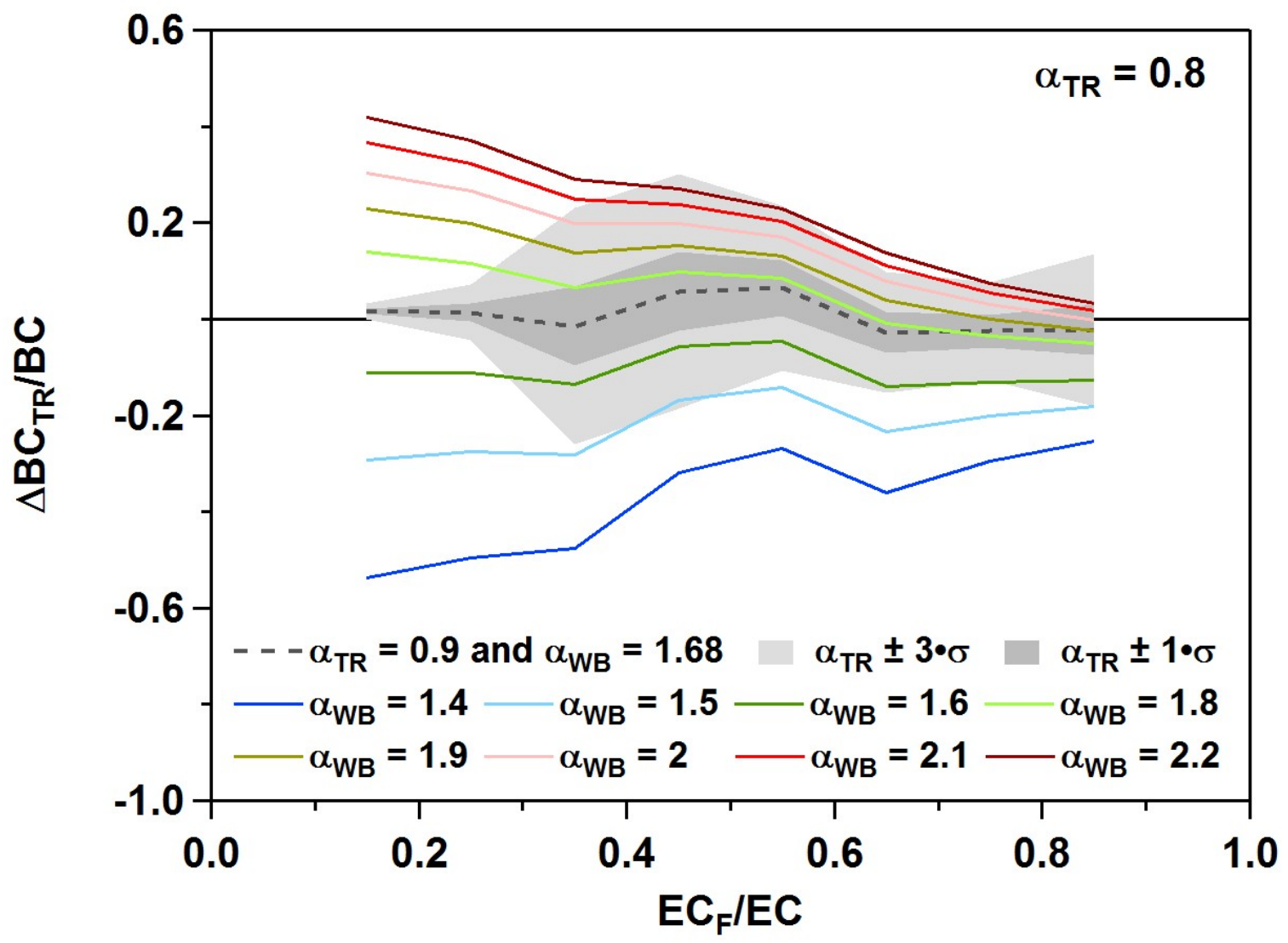

Figure S2: Residuals of $\mathrm{BC}_{\mathrm{TR}} / \mathrm{BC}$ compared to $\mathrm{EC}_{\mathrm{F}} / \mathrm{EC}\left(\Delta \mathrm{BC}_{\mathrm{TR}} / \mathrm{BC}\right)$ as a function of $\mathrm{EC}_{\mathrm{F}} / \mathrm{EC}$ for $\alpha_{\mathrm{TR}}=0.8$ and $\alpha_{\mathrm{WB}}=1.4-2.2$ and using the wavelength pair $470 \mathrm{~nm}$ and $950 \mathrm{~nm}$. Average $\Delta \mathrm{BC}_{\mathrm{TR}} / \mathrm{BC}$ values for $\mathrm{EC}_{\mathrm{F}} / \mathrm{EC}$ bins of 0.1 are displayed. The dashed grey line denotes the best $\alpha$ pair $\left(\alpha_{\mathrm{TR}}=0.9\right.$ and $\left.\alpha_{\mathrm{WB}}=1.68\right)$ as obtained in Sect. 3.2.1 and the dark and light grey shaded areas mark the $1 \sigma$ (standard deviation) and $3 \sigma$ of $\Delta \mathrm{BC}_{\mathrm{TR}} / \mathrm{BC}$ per $\mathrm{EC}_{\mathrm{F}} / \mathrm{EC}$ bin for this best $\alpha$ pair. 

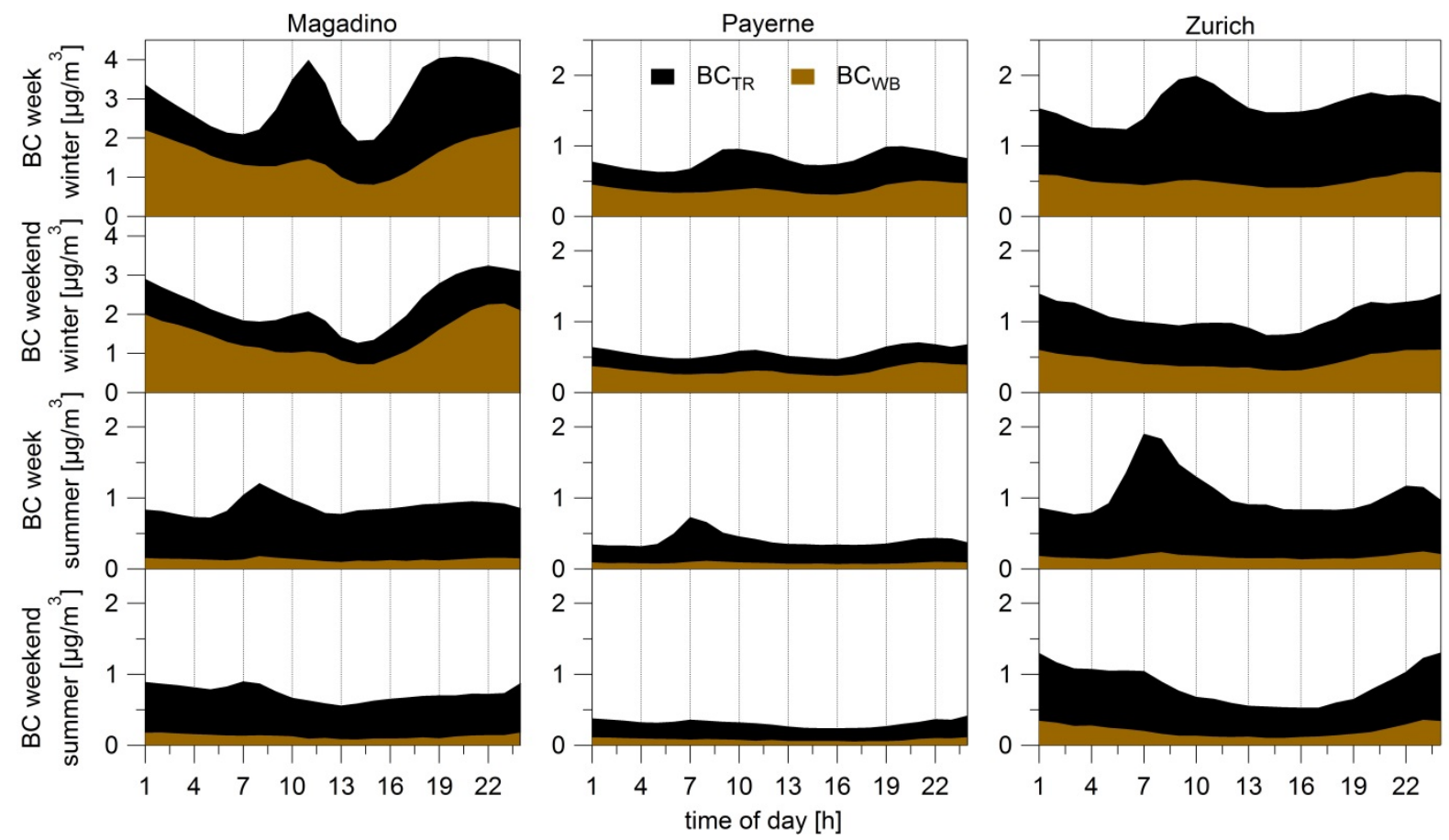

Figure S3: Diurnal cycles of BC for the stations MAG, PAY and ZUR - 1 h averages from 2009 to 2012. $\mathrm{BC}_{\mathrm{WB}}$ and $\mathrm{BC}_{\mathrm{TR}}$ were calculated using the best $\alpha$ pair $\left(\alpha_{\mathrm{TR}}=0.9\right.$ and $\left.\alpha_{\mathrm{WB}}=1.68\right)$ as obtained in Sect. 3.2.1 and using the wavelength pair $470 \mathrm{~nm}$ and $950 \mathrm{~nm}$. The split uncertainty between $\mathrm{BC}_{\mathrm{WB}}$ and $\mathrm{BC}_{\mathrm{TR}}\left(\Delta \mathrm{BC}_{\mathrm{TR}} / \mathrm{BC}\right)$ is $\max .0 .04 \mu \mathrm{g} \mathrm{m}^{-3}$.
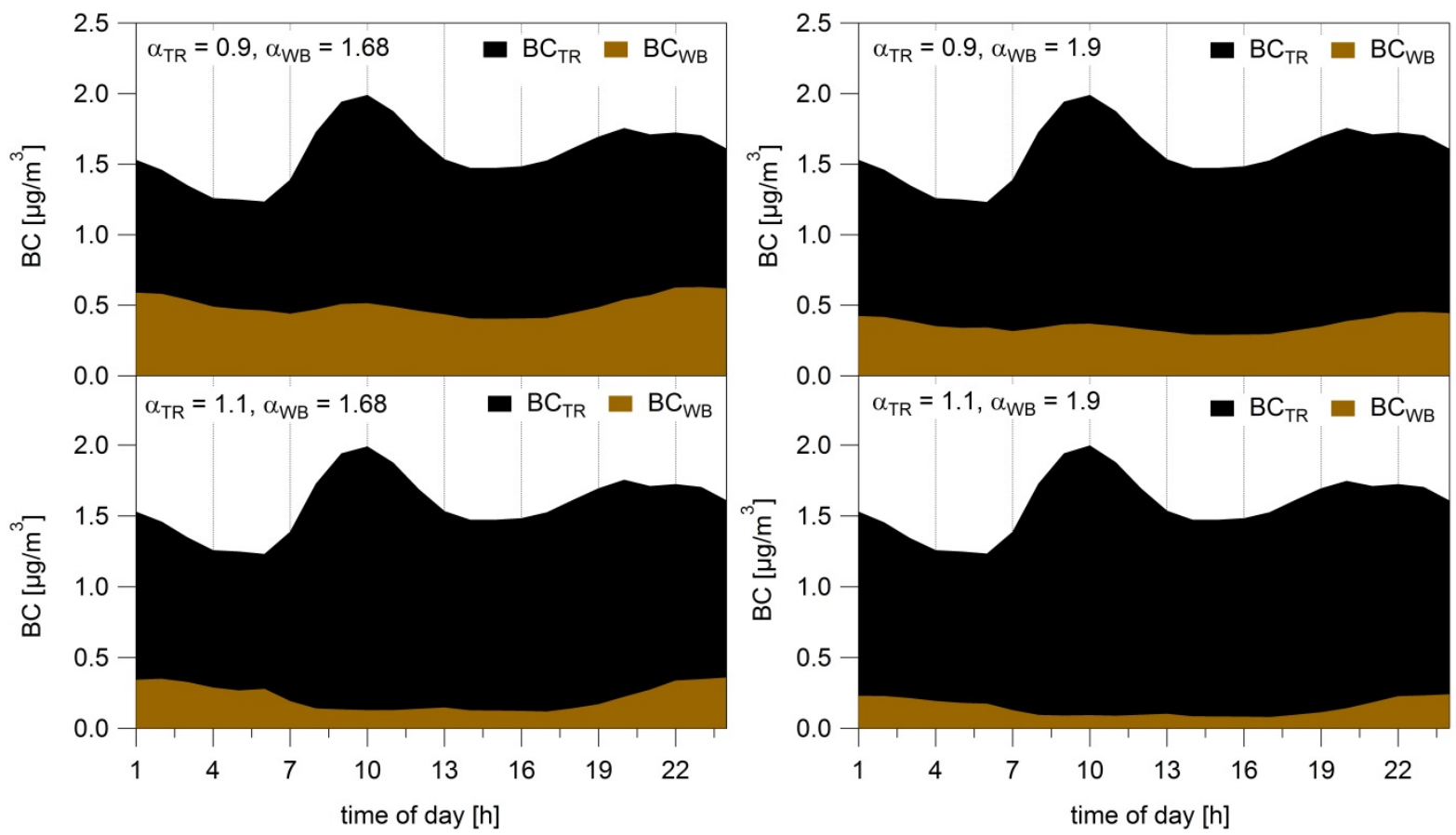

Figure S4: Diurnal cycles of BC for ZUR - 1h averages for winter week days from 2009 to 2012 calculated with different $\alpha$ combinations and using the wavelength pair $470 \mathrm{~nm}$ and 950 nm. 